

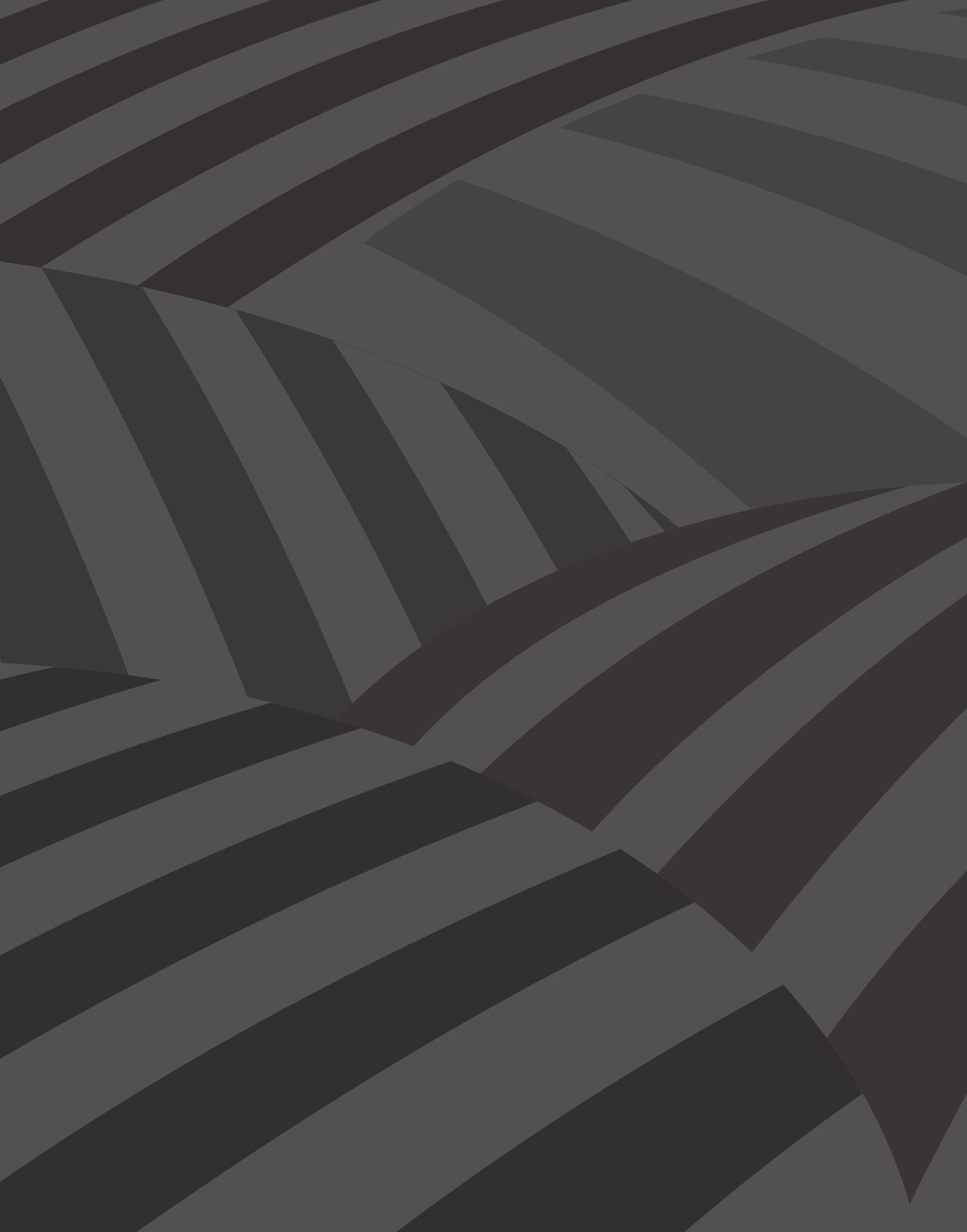




\section{Apuntes para entender la violencia sexual contra los hombres en el marco del conflicto armado colombiano}

Por Paulín Daniela López Gómez*

Resumen: en medio de la guerra, uno de los tipos de violencia más recurrentes es la sexual, por medio de la cual, se convierte el cuerpo en un campo de batalla, en un transmisor de la crueldad y en campo de dolor extremo. Sin embargo, hasta hoy, es muy poco lo que se sabe sobre esta violencia en contra de los hombres, en parte, por la falta de denuncia y por la creencia de que las únicas protagonistas en estos casos son las mujeres. Con base en lo anterior, este documento presenta un acercamiento a la violencia sexual contra los hombres en el marco del conflicto armado colombiano, trabajo que se llevó a cabo mediante la consulta de prensa, entrevistas con funcionarios públicos, trabajo de campo, análisis de fuentes secundarias, sentencias de paramilitares acogidos a Justicia y Paz y los informes de las denuncias y reportes de Derechos Humanos.

Palabras clave: violencia sexual, tortura, feminización, homosexualización, masculinidad hegemónica, exceso, cuerpo.

\section{Remarks for Understanding Sexual Violence against Men within the Context of the Colombian Armed Conflict}

Abstract: In the midst of war, one of the most recurrent types of violence is sexual, by means of which, the body becomes a battlefield, a transmitter of cruelty and a field of extreme pain. However, until now, very little is known about this violence against men, in part because of the lack of denunciation and the belief that sexual violence only happens against women. Based on the foregoing, this article presents an approach to sexual violence against men in the context of the Colombian armed conflict.

This work was carried out through press consultation, interviews with public officials, field work, analysis of secondary sources, sentences of paramilitaries under Justice and Peace and consultation of complaints and reports on human rights reports.

* Historiadora de la Universidad Javeriana. Maestría en Ciencia Política de la Universidad de los Andes. Analista de prensa del Centro de Investigación y Educación Popular Cinep. Correo: dlopez@cinep.org.co 
Keywords: sexual violence, torture, feminization, homosexualization, hegemonic masculinity, excess, body.

Cómo citar este artículo: López, Paulín Daniela (2018). Apuntes para entender la violencia sexual contra los hombres en el marco del conflicto armado colombiano. Revista Controversia, 210, 83-133.

Fecha de recepción: 24 de enero del 2018

Fecha de aprobación: 4 de abril del 2018

\section{Introducción}

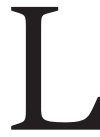

a violencia sexual ha sido una práctica presente en casi todos los conflictos a nivel mundial. Por lo general, las mujeres han sido las mayores víctimas de este tipo de violencia y su reconocimiento, a pesar de las cifras, ha sido relativamente reciente. Fue a partir de 1945 cuando empezó una cierta visibilización, aun sin nombrarse todavía como tal. Posteriormente, el IV acuerdo de Ginebra en 1949, Título III, sección I, artículo 27, y sus protocolos adicionales (I y II de 1977) fueron más específicos respecto a tratos denigrantes; allí se prohibió formalmente la violación. Luego, en los años noventa dos hitos importantes para este tipo de violencia fueron los tribunales internacionales de Yugoslavia y Ruanda (Ambos, 2012, p. 19). Ya para 1998, el Estatuto de Roma de la Corte Penal Internacional definió como crimen de lesa humanidad todo delito con motivo de género y el Protocolo de Estambul, emitido en 2014 por Naciones Unidas, reconoció como tortura a la violencia sexual. Esto ha facilitado la identificación de este tipo de violencia tanto en las mujeres como en los niños y en la población LGTBI, quienes también reportan altas cifras de violencia sexual, debido a su orientación, tanto en los conflictos armados como en las situaciones cotidianas.

Recientemente, los estudios, estrategias y rutas que se piensan frente a las víctimas mujeres y población LGTBI han aumentado, lo cual ha tenido incidencia en el reconocimiento de la violencia contra ellos y en 
su condición de vulnerabilidad, causada por los patrones de discriminación y desigualdad que, históricamente, han experimentado. No cabe duda de que estos esfuerzos han sido trascendentales y que aún hacen falta muchos más, pues hasta el día de hoy la violencia contra las mujeres y la comunidad LGTBI sigue en aumento. También es innegable que los principales victimarios han sido los hombres y que esto hace parte de una desigualdad de género que domina a nuestra sociedad.

Sin embargo, frente a la situación de la violencia sexual contra los hombres, los estudios y esfuerzos por tratarla y comprenderla han sido muy débiles. Por lo tanto, el presente artículo pretende visibilizarlos como víctimas de violencia sexual, porque se considera que su desconocimiento contribuye a la inequidad de género, hace prevalecer una masculinidad hegemónica arraigada en la sociedad — cuya base es la fortaleza, inquebrantabilidad, insensibilidad y valentía- y perpetua el supuesto de que la mujer es la única víctima de agresiones sexuales, por su condición de mujer, lo que la hace vulnerable, objeto de deseos sexuales de todo tipo y, en últimas, “susceptible de violar”. Además, esta clasificación imposibilita que esos hombres que han sido violentados, y no entienden ni saben cómo tratar su situación, sean atendidos. Muchos no se perdonan por lo que les sucedió y a muchos no los perdona la sociedad por no haberse defendido, por haberse dejado, en definitiva, por no "haber sido hombres"; por lo tanto, encuentran burla, estigma e incredulidad frente a sus experiencias.

Hecha esta aclaración, este artículo se dedica a reconstruir la violencia sexual contra los hombres en el marco del conflicto armado colombiano. No incluye en el análisis a los niños, niñas y adolescentes ni a las personas con orientaciones diversas. Ellos ya han sido reconocidos, de cierta forma, y, en parte, han sido identificadas las causas de las agresiones, caso contrario al del hombre heterosexual.

Para ello, se hizo una investigación en la que hubo una consulta detallada de los estudios sobre el tema en el escenario nacional e internacional, 
el cual fue el que más aportes brindó para comprender este tipo de violencia. Con este objetivo, se abordaron trabajos desde la ciencia política, la sociología y la criminalística y se hizo una revisión de prensa nacional e internacional, cuyo fin era, por un lado, encontrar si se reconocía la violencia sexual contra hombres, y por el otro, rastrear algunos casos de víctimas.

Asimismo, se practicaron entrevistas a funcionarias expertas en género de la Unidad de Víctimas y a la delegada para los derechos de las mujeres y asuntos de género de la Defensoría del Pueblo. Se indagó por el tratamiento de estos casos en Medicina Legal, Fiscalía General de la Nación, Ministerio del Interior y en Centros de Investigación como Memoria Histórica y Centro de Investigación y Educación Popular (Cinep). Igualmente, se consultaron los informes publicados por ACNUR, la ONU, Amnistía Internacional, la Organización Internacional de Migraciones y Cruz Roja Internacional. Se consultaron sitios especializados como Refugee Law Project, cuyo creador fue Criws Dolan; Bristlecone Project (Portraits and Biographies of Male Survivors), creado por Alstair Hikton; y The South-South Institute on Sexual Violence Against Men and Boys y Genderside Watch. Estas cuatro iniciativas reportan casos de hombres víctimas de violencia sexual y han hecho un importante avance mundial no solo sobre la visibilización de esta problemática, sino sobre el tratamiento y superación de estos hechos.

En cuanto a la reconstrucción y caracterización de los 216 casos de hombres violentados sexualmente en el marco del conflicto armado colombiano, se consultaron los boletines Justicia y Paz entre 1988 y 1996, la revista Noche y Niebla entre los años 1996 y 2017 y 31 sentencias de paramilitares que se acogieron a Justicia y Paz. A su vez, se revisaron informes de Memoria Histórica, Humanas Colombia, Ruta Pacífica de las Mujeres, El libro negro de la represión, Nunca Más Colombia, informes del Movimiento de Víctimas de Crímenes de Estado (Movice) y reportes de la Fiscalía General de la Nación. Adicionalmente, se hizo trabajo de campo en un municipio ubicado en el Chocó — cuyo nombre se 
mantiene en reserva por petición de los miembros de la comunidad-, en octubre y noviembre del año 2013 y octubre del año 2016.

Con base en toda la información recopilada, el artículo se divide en cuatro partes: 1) Estado del arte y marco conceptual; 2) La violencia sexual contra hombres desde algunas instituciones colombianas; 3) Análisis de los casos identificados a lo largo de la investigación; y 4) Conclusiones.

\section{Marco conceptual}

La violencia sexual es entendida como cualquier tipo de violencia, ya sea física y/o psicológica, dirigida a las características sexuales de una persona. Dentro de esta definición se resaltan tres tipos fundamentales. El primero es la violación sexual, definida como el acto de penetración; el segundo es la agresión física a determinadas zonas del cuerpo, en la que se incluye la mutilación o castración, los golpes y otros métodos de agresión; y la tercera consiste en los desnudos forzosos, acompañados por lo general de insultos, burlas, amenazas y ofensas dirigidas a atacar su identidad de género (Ruvinsky, 2012, p. 14). Cabe aclarar que se puede encontrar otro tipo de agresiones como obligar al hombre a violar o maltratar a una mujer, presenciar su violación y ejercer la prostitución; sin embargo, solo se tendrán en cuentan los primeros tres casos.

Adicionalmente la violencia sexual se define también como una modalidad de violencia de género, como una forma de dominio y poder por medio de actos y agresiones sexuales (Centro Nacional de Memoria Histórica, 2017, p. 21). Este dominio y poder que se resalta a la hora de hablar de la violencia sexual se explica en la presente investigación a partir de tres categorías que han sido utilizadas por investigadores como Sivakumarán (2010), Henry (2016) y Capers (2011), para analizar estos casos en conflictos de otros países: la femininización, la homosexualización y la castración, que responden al deseo de generar humillación y reducción de la posición del hombre frente a la comunidad, a 
su familia y así mismo. Estos elementos pretenden reducir la hombría de la víctima a partir de su acercamiento a lo femenino por actitudes de debilidad, dolor, llanto e impotencia (feminización); de considerarlo homosexual por el hecho de ser un hombre violentado sexualmente por otro hombre y no poder evitarlo (la homosexualización); y a partir de la mutilación de sus órganos sexuales (castración).

A su vez, estos elementos están enmarcados dentro de un tipo de relación de género en el que la masculinidad hegemónica cobra un papel importante. Aquí es clave tener en cuenta a Robert Connell (1995), quien plantea que la masculinidad no es algo per se, sino que es histórica y se construye a partir de modos de ser relacionados con el dominio y el poder, enmarcados en estructuras cambiantes (p. 115-122). Es así que se consolida una forma dominante de "ser hombre" y las experiencias sociales configuran presiones que hacen que los hombres se adapten a lo que es ser un “varón” (Viveros, 2001, p. 54). En este orden de ideas, hay que tener en cuenta que las relaciones de género entre los hombres son dinámicas y diferenciadas. Por lo tanto, muchas veces, entre los mismos hombres hay tensiones respecto a la masculinidad.

En la violencia sexual, por ejemplo, se puede ver una minimización de la masculinidad y hombría de la víctima y una sobreexaltación de la masculinidad del victimario y del modelo normativo del "ser hombre". Esto explica por qué en muchas zonas del país se violentan sexualmente a los hombres como una forma de minar el liderazgo en las comunidades, pues un hombre violado no puede ser la cabeza de la comunidad.

Ahora bien, algunos actos de violencia sexual, como la violación, están contenidos dentro de una categoría mucho más amplia, que es la tortura (Ambos, 2012). Sin embargo, la reflexión que se hace en torno a la violencia sexual, en la presente investigación, es que se debe analizar y estudiar de forma separada de la tortura, con el fin de que no se invisibilice como ha sucedido en el caso de los hombres, pues es muy común ver que, al hablar de las afectaciones de los hombres en los 
conflictos, se hace referencia a hombres torturados y no se profundiza en el tipo de violencias que están contenidas allí. Adicionalmente, se considera que agresiones como golpes en los testículos, choques eléctricos o desnudos forzosos, en el caso de los hombres, son agresiones al cuerpo calificables dentro de la categoría de tortura, sin tener en cuenta su componente sexual; por lo tanto, muchos casos de violencia sexual contra ellos se han ocultado en la generalidad de tortura ${ }^{1}$ y esto ha influido en el desconocimiento de dicha problemática.

Al hablar de violencia sexual contra el hombre e indagar por casos ocurridos en el marco del conflicto armado colombiano, se encontraron hechos ubicados en un plano diferente, que, si bien no entran propiamente en la problemática de violencia sexual contra ellos, sí deben ser tenidos en cuenta, dado su componente simbólico ligado a la sexualidad y su rol en la sociedad.

Es importante mencionar que, junto a la violencia sexual, se habla de agresiones que suceden fundamentalmente cuando la víctima se encuentra viva, pero en Colombia también se encontró que, después de la muerte, el cuerpo masculino ha sufrido agresiones con connotaciones sexuales muy fuertes, a pesar de desconocerse si en vida fue violentado o no. Por ejemplo, muchos cuerpos masculinos han sido encontrados con sus testículos en la boca o en posiciones con connotaciones sexuales, como una forma de denigrar a la víctima y como un trasmisor de mensajes a las comunidades. Estos casos también se incluyen en esta investigación, porque hacen parte de un tipo de abuso al cuerpo masculino sin vida con connotaciones sexuales, que pretende, al igual que la violencia sexual, minar su posición en la comunidad a través de la humillación y la reducción de su masculinidad.

1 Al realizar la búsqueda de casos de hombres víctimas de violencia sexual en Colombia, se exploraron varias bases de datos en las que se encontró que, muchos casos clasificados como tortura exponían dentro de las narraciones actos de violencia sexual; sin embargo, estos no eran catalogados como tal, a pesar de existir una categoría que se refería a este tipo de violencia. Con las mujeres la situación es diferente, pues, al caracterizar sus casos, por lo general se encontraban clasificados con doble categoría, la de tortura y la de violencia sexual. 
Ahora bien, tanto en los casos de violencia sexual como en los de este último tipo de abuso, es necesario el análisis del cuerpo en relación con la violencia. En razón a lo anterior, este ha sido comprendido desde dos dimensiones. La dimensión física, como el escenario de producción de dolor y sufrimiento. Como bien dice Sofsky (1997), en "la tortura la persona es invadida por el dolor, experimenta su cuerpo como nunca antes lo hizo. Su carne pasa a ser una realidad total. La persona torturada es solo cuerpo y nada más” (p. 337). En este caso, la violencia sexual actúa, entre otras cosas, también como forma de tortura. La segunda dimensión es la simbólica, en la que el cuerpo se convierte en un trasmisor de mensajes, un escenario de confrontación, un símbolo de conquista y derrota para ese otro/enemigo a quien representa ese cuerpo, ya sea vivo o muerto.

En el caso de los abusos en el cuerpo sin vida con connotación sexual, como lo hace notar Blair (2005), "El cuerpo muerto es el lugar donde ocurren las violencias, y como tal, es probable que la violencia hable en los actos ejercidos sobre los cuerpos, que se exprese en un lenguaje corporal” (p. 47). El cuerpo, entonces, es el instrumento por el cual se "mata, remata y contramata” (Uribe, 1978, pp. 162-169). En ambos casos, la violencia sexual y los abusos al cuerpo sin vida con connotaciones sexuales, el exceso como categoría explicativa es fundamental, por lo tanto se retoman los análisis de Elsa Blair $(2005,2012)$ y Sofsky (1997), a saber, el exceso en la carga simbólica inscrita en las maneras utilizadas para ejecutar actos violentos, para nombrarlos y mostrarlos:

El exceso trabaja con los cuerpos, ya sea en espectáculo público o como tortura encubierta. Ni siquiera tiene la muerte como objetivo principal. El exceso transforma la matanza en suceso. Se toma el tiempo que necesita. Demuestra la vejación del hombre, su destrucción total a partir de todas las partes de su cuerpo y de lo que representa para él y para la sociedad. (Sofsky, 1997, p. 338) 
El exceso en la dimensión física es una forma de derrotar, maltratar, producir dolor, terror y deshumanizar en su máxima expresión; por lo tanto, se expone el cuerpo en determinadas posiciones, se trasladan los genitales a la boca, se empala y se maltratan los testículos.

\section{Qué se sabe sobre la violencia sexual contra el hombre}

Aun cuando, como se ha dicho desde el inicio, es muy poco lo que se sabe del tema, se pueden encontrar algunas investigaciones que han arrojado importantes elementos de análisis, sobre todo, aquellos elaborados en Estados Unidos y Europa.

Esta ausencia de información sobre la violencia sexual contra el hombre es fruto de varios aspectos: 1) la falta de vías y estrategias por parte de las entidades especializadas para promover la denuncia, pues hay una carencia en la creación de estrategias exclusiva para los hombres. Cabe aclarar que las vías para dialogar con las mujeres sobre este tema difieren de manera notable de las de los hombres; 2) la definición excluyente de la violencia sexual proporcionada por las organizaciones internacionales y otras instancias, pues, al definir la violencia sexual, se tiende únicamente a mencionar como víctimas a las mujeres y como victimarios a los hombres; 3) la poca información reportada, fruto de las escasas denuncias interpuestas por los hombres, lo cual no tiene nada que ver con la frecuencia o no de la ocurrencia del hecho; y 4) el uso de la categoría de tortura como forma de ocultamiento de hechos de violencia sexual contra hombres, como ya se mencionó anteriormente.

Esto hace parte de una dinámica en la que, como bien lo ha estudiado Ruvinsky (2009), hay una imposibilidad de asociar a la "víctima de violencia sexual" con la masculinidad, es decir que estamos de frente a un problema que ella ha denominado feminización de la categoría "víctima de violencia sexual" o, en otras palabras, el reconocimiento de la mujer como única víctima de este tipo de violencia (p. 64). 
A pesar de los escuetos estudios al respecto, se pueden definir tres grandes líneas a partir de los análisis que hay hasta el momento. La primera de ellas se centra en la identificación de la atención dada a la violencia sexual contra hombres por parte de los organismos internacionales. La segunda se preocupa por definir la violencia sexual, de tal forma que incluya al hombre, y sus causas y consecuencias a través del estudio de caso. Y la tercera se enfoca en establecer vías para visibilizar este tipo de hechos y determinar estrategias de tratamiento.

En cuanto a los estudios sobre el trato que amerita este tipo de violencia por los organismos internacionales, marcos jurídicos nacionales, campo jurídico del Derecho Internacional Humanitario, Derecho Penal Internacional y organizaciones de atención de víctimas, se puede identificar un conceso en la afirmación de que, el mal uso de categorías como género, sexo y homosexualidad, han contribuido a que la víctima de violencia sexual sea relacionada exclusivamente con la mujer y por lo tanto se invisibilice al hombre (Khan, 2002), (Lewis, 2009) (Carpenter, 2006 ), (Zawati, 2007) (Sivakumarán, 2010). También se tiene en cuenta el factor cultural como elemento que influye en el desconocimiento del hombre como víctima (Del Zotto, 2002, p. 40); adicionalmente, se considera que hay una clasificación estereotipada en el Derecho Internacional, una falta de vocabulario para este tipo de experiencias y una reducción del concepto de violencia sexual y de género.

Debido a estos elementos, las estrategias y rutas para generar y facilitar la denuncia de los hombres son casi inexistentes. Esta ausencia también es resaltada por otros autores como Hilmi Zawati (2007), en su trabajo sobre la impunidad de la violencia sexual contra el hombre en los casos de Bosnia-Hersegovina, Croacia e Irak; Sandesh Sivakumarán (2010), en su análisis sobre algunos espacios en los que la onU se ha referido a la violencia sexual sin hacer mención directa al hombre, lo que considera parte de una tendencia a describir una violencia no caracterizada y relacionada con la tortura; Henry (2016) y su explicación sobre la jerarquía de las víctimas; Charles Carpenter (2006), quien se 
propone ubicar las agresiones sufridas por los hombres como el desplazamiento, la masacre selectiva y el reclutamiento forzado, desde una perspectiva de género, y analizar el discurso de pronunciamientos e informes de Naciones Unidas, ACNUR, Human Rights Watch, entre otros, frente a los cuales determina la poca o nula referencia a los hombres cuando se habla de violencia de género y de violencia sexual, lo que repercute en la poca atención prestada; y Elizabeth Kramer (1998), Lara Stemple (2009), Anna Philo Gorrid (2015) y Chris Anderson, quienes identifican, a partir de una lectura detallada de varias leyes e informes de violencia sexual, un lenguaje que hace referencia a lo femenino y excluye a lo masculino como víctima.

En relación con lo anterior, Lara Stemple (2009), por ejemplo, señala que, de 4076 organizaciones gubernamentales revisadas en su investigación, únicamente el $3 \%$ mencionan las experiencias de los hombres, a pesar de que estos hechos suceden en diferentes escenarios como el doméstico, el carcelario, el educativo, en los conflictos armados y callejeros (p. 618).

De hecho, la inclusión del hombre como víctima es relativamente nueva y hasta ahora se hacen algunas menciones a él. Por ejemplo, en la Corte Interamericana de Derechos Humanos, como lo explican Moser y Leyva Morelos (2015, p. 81), se pueden establecer tres momentos. El primero, comprendido entre 1988 y noviembre del 2006, en el que se tenía conocimiento sobre un tipo de violencia que incluía el maltrato a genitales, pero no era considerado como violencia sexual. El segundo, entre el 2006 y 2014, en el que ya se había aceptado la existencia de violencia sexual, pero únicamente en las mujeres. Y el tercero, a partir de 2014, como resultado de un caso colombiano en el que se reconoce que algunos de los maltratos que recibió un hombre durante la toma y la retoma del Palacio de Justicia son, efectivamente, un tipo de violencia sexual.

Ahora bien, en cuanto a las razones por las cuales se recurre a este tipo de agresiones, las cuales suelen ser invisibilizadas por las víctimas, los 
victimarios y la sociedad en general, encontramos los trabajos de Sandesh Sivakumarán (2015), Hilmi Zabati (2006), Khan (2002), Aliraza Javaid $(2016,2015,2014)$, Lees (2002), Stanko (1995), Groth y Burgues (1980) y Elizabeth Kramer (1998). Estos autores han introducido categorías importantes como "la mancha homosexual", "la masculinidad hegemónica”, el “sesgo antigay” y la “feminización del hombre”.

Ellos señalan algunas motivaciones para ejercer la violencia sexual contra los hombres: 1) la búsqueda de control y poder sobre la víctima (el hombre) y la comunidad que este representa; 2) la adquisición de información; y 3) el castigo. Estos tres elementos están atravesados por lo que Aliraza Javaid $(2014,2016)$ ha retomado de Lees (1997) y Stanko (1995): “la masculinidad hegemónica”, categoría que hoy en día ya se ha estudiado ampliamente en Colombia y en otros países².

Estos tres últimos autores aclaran que en las sociedades hay una masculinidad dominante y le atribuyen al hombre una serie de características que permanentemente se reivindican y se hacen públicas, de tal forma que, cuando un hombre viola o agrede al otro, lo que está en juego es la permanencia y la reivindicación de esta masculinidad sobre la del hombre agredido, que a partir de este momento representa una masculinidad subordinada (Javaid, 2016, p. 284). Esto quiere decir que el victimario está en ejercicio constante de realce de su masculinidad en detrimento de la de su víctima (Groth y Burgues, 1980, p. 284). La violencia sexual, sea esta la violación, la mutilación o el desnudo, lleva consigo un interés de minimizar la posición de la víctima y maximizar la del victimario. Esto pudo verse, por ejemplo, en la cárcel de Irak, en donde soldados americanos usaron, dentro de las estrategias más recurrentes, los abusos sexuales, desnudos forzados y maltratos acompa-

2 Ver los trabajos de Mara Viveros sobre género e identidad y la masculinidad en Colombia. Ver los trabajos de Michael Kaufman sobre experiencias contradictorias del poder entre los hombres. 
ñados de burlas y fotografías denigrantes, como lo describe el informe investigativo:

Abuso en Abu Ghraib: (...) 3) (U) Los abusos violentos o sexuales intencionales incluyen actos que causan daños corporales mediante el uso de fuerza ilegal y delitos sexuales que incluyen, entre otros, violaciones, sodomía y agresiones indecentes. Ningún soldado o contratista creía que estos abusos estuvieran permitidos por ninguna política u orientación. De ser comprobado, estas acciones serían actos delictivos. Las causas principales de los abusos sexuales y violentos fueron relativamente sencillas: mala conducta individual, claramente en violación de la ley, la política y la doctrina y en contra de los valores del Ejército. (Jones, Fay, 2004, p.4)

Lo mismo se identificó en los conflictos de Yugoslavia, en donde se reportaron aproximadamente 4000 hombres croatas víctimas de violencia sexual (Zawati, 2007, p. 35), en Croacia (Zwanikken y Ketting, 2004) y Serbia (Alison, 2007, p. 86). En Congo hubo reportes de 760000 hombres. En Sri Lanka, el $21 \%$ de los hombres que estuvieron en centros de tortura informaron haber sido violados. En El Salvador, el $76 \%$ de los presos políticos hombres encuestados en 1980 describieronn al menos un incidente de tortura sexual. En Sarajevo, de 6000 reclusos, se encontró que el 80 \% de los hombres hizo reportes de violación (Storr, 2011). En Sudán y Darfur, se obtuvieron 1136 narraciones de hombres víctimas (Ferrales, Brehm y Mcelrath, 2016, p. 570). En Irak, se contaron más de cincuenta hombres violados (Zawati, 2007, p. 34). Casos similares se presentaron en El Congo, Cosovo, Uganda y Burundí (Gettleman, 2009) y, actualmente, en el conflicto de Siria ocurren situaciones parecidas con los refugiados en Irak, Líbano y Jordania, en donde, según la investigación realizada por Sarah Chynoweth (2017) en labor para la ONU y la ACNUR, diariamente violan a los hombres.

La violencia sexual funciona como un arma o estrategia de guerra por excelencia tanto en hombres como en mujeres. Ahora bien, estas manifestaciones de poder y control por parte del victimario y la mini- 
mización de la víctima son posibles a través de lo que Freivogel (2010), Lewis (2009), Mackinnon (1997), Del Zotto y Jones (2002) y Ruvinsky (2012) han identificado como la feminización del hombre. En razón a esta, cada agresión, por lo menos en escenarios de guerra, consiste en reducir al máximo la masculinidad de hombre mediante su feminización, que conduce a su humillación y derrota (Lewis, 2009, pp. 7-8) y, con esta, a la derrota de su familia y la de su comunidad, frente a lo cual, cabe recordar que, como se ha dicho atrás, generalmente la violación no es entendida como compatible con la masculinidad.

Otros autores como Ferrales, Brehm y Mcelrath (2016) y Capers (2011, pp. 572-576) complementan el mecanismo de la feminización con tres más, de acuerdo al tipo de violencia sexual. Estos son: la homosexualización, la castración y la vulnerabilidad a través del desnudo forzado.

Con base en lo mencionado, se resaltan algunos mitos que giran en torno a la violencia sexual contra el hombre, los cuales son: 1) la violencia sexual como exclusiva de los homosexuales (Kramer, 1998, pp. 311315); 2) la violencia sexual contra el hombre como hecho esporádico; y 3) El evento como un acto cuya motivación principal es el deseo. Esta relación entre la violencia sexual de un hombre y la homosexualidad es lo que Sivakumarán ha denominada la mancha de la homosexualidad, la cual ha imposibilitado la visibilización de las víctimas.

Como bien lo dice Michael Davies y Paul Roger (2006):

Un acercamiento a la violación masculina que asume que todas las víctimas son homosexuales no sirve, pues además de su inexactitud, sería perpetuar aún más la posición sesgada de que los hombres reales deben ser capaces de evitar su propia violación. (p. 633) [traducción propia].

Finalmente, es importante mencionar algunos trabajos sobre violencia sexual contra el hombre en Colombia. A pesar de que casi no se ha explorado este tema, se pudieron encontrar cuatro investigaciones: cuatro 
tesis, dos de maestría y dos de pregrado, que intentan abordar la problemática de los hombres en el marco del conflicto armado colombiano.

La primera de ellas fue presentada en la Universidad de los Andes y dirigida por María Emma Wills (Obando, 2008). Intenta abordar la problemática desde los pocos datos que se tienen en Colombia y hace un acercamiento teórico; pero, dada la escasez de las cifras y reportes, no analiza casos específicos. La segunda tesis es de Margareth Figueroa, presentada en el 2017 en la Universidad de la Sabana; se plantea la problemática y tiene un acercamiento mayor con cifras de diferentes entidades colombianas. Su objetivo principal es sensibilizar, a través de videojuegos, la comprensión de los derechos humanos. La tercera fue presentada en la Universidad Militar Nueva Granada y su fin es explorar la violencia sexual tanto en hombres como mujeres en Colombia. Por último, la cuarta es la tesis presentada por Samed Vargas en la Universidad Javeriana, en la que incluye el estudio de población LGTBI; por lo tanto, extiende más su exploración y hace importantes aportes para la compresión de la violencia sexual.

Finalmente, es importante mencionar los tres informes de prensa publicados en el periódico El Tiempo por Johana Álvarez (12 de diciembre de 2009) y Tatiana Escárraga (6 de septiembre de 2014), que no solo se aproximan al tema en términos de cifras, sino que muestra algunas narraciones de hombres víctimas.

\section{Violencia sexual contra el hombre en Colombia. Una realidad invisible}

En Colombia, la violencia sexual contra el hombre es una problemática de la que poco se habla y de la que no se tienen mayores informes. A pesar de que se reportan algunas cifras en instituciones como Medicina Legal, Unidad de Víctimas, Defensoría del Pueblo, Fiscalía General de la Nación, entre otras, el abordaje de este tipo de hechos es mínimo y, por ende, la atención que suscitan. Su invisibilización se atribuye, por 
lo general, a los pocos datos que manejan las diferentes entidades, a razón de las exiguas denuncias. No obstante, tampoco se observa un esfuerzo de mayor envergadura por investigar los que se reportan.

Al revisar, por ejemplo, los informes de Medicina Legal desde 1999 hasta el 2016, se puede evidenciar una tendencia a analizar la violencia sexual como aquella que sufren únicamente las mujeres. Aun cuando, al inicio de cada informe, la definición de esta violencia es incluyente, el desarrollo del análisis y las observaciones se reducen a la mujer. Por ejemplo, en la Guía práctica para la investigación de los delitos sexuales contra mujeres ( $s . f$.), esta violencia se reduce meramente a la mujer, de tal forma que ignora las cifras en las que los hombres se reportan como víctimas y hace pensar que las estrategias que se idean para contrarrestar esta problemática solo están dirigidas a las mujeres.

Lo mismo sucede en el informe Modelo de Atención Integral en Salud para víctimas de violencia sexual, presentado en el 2011 por Medicina legal (2011), y en el informe de violencia sexual que se enmarca entre el 2009 y el 2014 (Medicina legal, 2014).

En el caso de los informes de la Unidad de Víctimas, la cobertura de la violencia sexual incluye a la población LGTBI. Lo anterior, en parte, se justifica debido las altas cifras que se han reportado sobre las agresiones sexuales por parte de varios actores armados hacia ellas. Asimismo, los informes develan el esfuerzo por definir directrices que permitan brindar una orientación útil tanto para las mujeres como para la población LGTBI; a saber, cómo indagar, qué tipo de preguntas se deben hacer y cómo deben reaccionar quienes reciben las denuncias. Además, estos especifican que la Unidad de Víctimas

Ha participado en las jornadas de declaración y denuncia que impulsa el Ministerio del Interior, en las cuales se brinda apoyo psicosocial para fortalecer la capacidad de las mujeres para la toma de decisiones, 
implementando la estrategia de reparación integral a mujeres víctimas de violencia sexual. (s. f., p. 4)

A pesar de todo, en ningún apartado menciona al hombre, lo cual se reafirma en la aclaración anterior, pues la ausencia se hace notoria cuando trata de los espacios, encuentros y apoyo psicosocial, que son casi exclusivos para las mujeres víctimas.

De cincuenta informes revisados, por lo menos siete hacen referencia al enfoque de género, a temáticas sobre el conflicto armado y la mujer e identidades con orientación sexual diversa. En uno de dichos informes, se define el enfoque de género, las orientaciones sexuales diversas, los tipos de violencia de género e incluso la violencia sexual contra la mujer; pero, más allá de mostrar algunas cifras, no se menciona el caso de los hombres. Adicionalmente, se exponen algunos mitos que giran en torno a la mujer y a las orientaciones sexuales diversas, pero nunca se visibilizan vinculados a la violencia sexual contra hombres, que explican, en parte, el sub registro.

En ese sentido, se indagó por las acciones particulares que se están implementando actualmente para atender dicha violencia en los hombres $y$, aunque algunas funcionarias encargadas de la parte de género mostraron interés y preocupación al respecto, explicaron que se estaban llevando a cabo algunas iniciativas como talleres de formación, pero que hasta el momento no se tenían directrices ni rutas específicas. Ellas también aclararon que no habían atendido aún ningún caso de hombres, pero que trabajaban para poder facilitar este tipo de acercamientos (Entrevista con las funcionarias de la Unidad de Víctimas, 2017).

En cuanto a la Defensoría del Pueblo, los informes defensoriales y algunas noticias publicadas desde el 2005 hasta el 2017 (275 documentos), en su mayoría, se dedican a analizar los derechos de las mujeres y asuntos de género, pero terminan haciendo énfasis tan solo en las mujeres y en las personas con orientaciones sexuales distintas. En dichos 
informes, se exponen las cifras de asesinatos, violencia sexual, feminicidio, asesinato de lideresas, discriminación y asesinato de personas miembros de la comunidad LGTBI, pero, en ninguno de los casos, se puede ver algún documento o referencia a los hombres como víctimas de violencia sexual.

Según un comunicado del 2017, el defensor del pueblo, Carlos Alfonso Negret, expresa sobre la violencia sexual en el marco del conflicto que:

Están en situación de vulnerabilidad las indígenas y afrodescendientes, personas con orientaciones sexuales e identidades de género diversas, así como adultas mayores víctimas de desplazamiento forzado. En este contexto, la Defensoría "lanza e institucionaliza su Plan de Acción Integral y Ruta de Atención para las mujeres sobrevivientes de actos de violencia sexual". Este plan es "el resultado de dos años de trabajo interno, en el que se recopilaron todos los protocolos y rutas de atención existentes al interior de la Entidad, para generar una única ruta que se enfoque en dar una atención integral que evite la revictimización”.

El defensor del Pueblo, Carlos Alfonso Negret Mosquera, en el marco de los 16 días de activismo contra la violencia de género, suscribió una Resolución Defensorial, mediante la cual se adoptan el mencionado Plan de Acción y Ruta de Atención. Estos nuevos instrumentos, "no solo dan cumplimiento a la orden judicial; garantizan también una articulación interna de la Entidad para responder de manera integral a esta grave problemática. Así, se atenderán de manera diferencial a mujeres indígenas, afro, niñas, adolescentes, desplazadas, lesbianas, trans, víctimas de conflicto”.

Como puede verse, los planes parecen estar dirigidos únicamente a las mujeres y no a los hombres sobrevivientes de violencia sexual. El Plan de Acción Integral y Ruta de Atención para las mujeres sobrevivientes de actos de violencia sexual, institucionalizados por la Defensoría del Pueblo, se acogen a la ruta de denuncia y atención para los casos; aunque cada postulado está propuesto de forma inclusiva (hombres y mujeres), 
los títulos y aclaraciones siempre se refieren a la mujer, lo que hace difícil que un hombre se acerque a radicar su denuncia y/o solicitar atención (ruta de atención integral para asesorar e instruir a las mujeres sobrevivientes de actos de violencia sexual en el marco del conflicto armado interno y el desplazamiento forzado por la violencia de la defensoría del pueblo, Auto 009 de 20159).

A pesar de esto, Carolina Tejada (2017), delegada para los derechos de las mujeres y asuntos de género, aclaró en entrevista que, si bien no hay referencias específicas a los hombres, ninguna ruta ni ley es excluyente frente a estos, quienes, por ende, tienen acceso a ellas igual que las mujeres. Sin embargo, se obtiene muy poca información sobre esta problemática, debido a la vergüenza o estigmatización que un hecho de este tipo produce en los hombres.

En cuanto a los informes de investigación liderados por Memoria Histórica, la Organización Internacional de Migraciones (OIM), ACNUR, Amnistía Internacional, entre otros, la situación es similar. Memoria Histórica expone que, de 86 informes revisados, seis hacen referencia a género, mujer en el conflicto armado, violencia sexual, conflicto y población LGTBI, pero ninguno analiza a fondo la problemática de los hombres.

En el caso del informe Crímenes que no prescriben (2015), únicamente se encuentran tres alusiones al hombre como víctima: la primera habla de los casos pendientes por investigación y se menciona el municipio de Villanueva, Arauca, como un lugar en donde se reportan situaciones de violencia sexual contra hombres (p. 217). La segunda explica que

aunque en las guerras los hombres suelen ser víctimas de agresiones físicas de manera más frecuente y mueren en mayor número, las mujeres suelen ser víctimas de hechos como el abuso sexual, que causan estrés postraumático en mayor medida, lo que ocasiona que ellas reporten mayores niveles de sufrimiento psicológico. (p. 167) 
La tercera es la aclaración de que el énfasis de la investigación no son los hombres, ya que, "por sus diferentes contextos, están expuestos a una gama de daños distintos a los de las mujeres” (p. 163).

Cabe mencionar con especial interés la segunda alusión, en la que se reafirma uno de los mitos alrededor de la violencia sexual: la consideración de que es única en las mujeres y que causa un mayor estrés en ellas que en los hombres. Esta afirmación es falsa, en tanto que existen altas cifras a nivel mundial que demuestran que los hombres han sido violentados sexualmente en el marco de diversos conflictos. Además, se ha comprobado, a través de diferentes ejercicios y campañas contra esta violencia, que tanto hombres como mujeres sufren el mismo estrés postraumático después de una situación como esta ${ }^{3}$.

Posteriormente, en el informe presentado en el 2017 también por Memoria Histórica, La guerra inscrita en el cuerpo. Informe nacional de violencia sexual en el conflicto armado, se explica, de cierta forma, la ausencia del tema vinculado a los hombres:

La movilización de los hombres como víctimas de violencia ha sido muy escasa y poco organizada, lo que contribuye enormemente a que sobre estas personas redunde la desatención y el miedo. Por las razones expuestas, sus voces no aparecen en este informe con la centralidad de las mujeres. (p. 16)

Dentro de los trabajos que mencionan al hombre como víctima, cabe resaltar el informe de ACNUR presentado en el 2012. A pesar de que este no alude a la situación particular de Colombia, sí menciona uno de los problemas más comunes aquí, el desplazamiento y el riesgo que corren también los hombres ante dicha situación. Según ACNUR,

3 Véase: Bristlecone Project. Portraits and Biographies of Male Survivors. 
La violencia sexual contra los hombres también es una amenaza en situaciones de desplazamiento y asilo. Cuando se enfrentan a graves problemas de subsistencia, tanto hombres como mujeres están en riesgo de explotación sexual y abuso a cambio de alojamiento y alimento. (p. 3)

A su vez, hace un llamado para que, como han sugerido estudiosos del tema (Anderson, citado en Philo Gorrrid, 2015, pp. 421-422; Stemple, 2009, p. 618; Carpenter, 2006, p. 37), se implemente un lenguaje más inclusivo que conciba al hombre como víctima real.

\section{Dinámica de la violencia sexual contra hombres en el conflicto armado}

La dinámica que se reconstruye a continuación toma casos de violencia sexual desde 1970 hasta el 2017, es decir que pasa por el Estatuto de Seguridad, las actividades iniciales de las guerrillas (FARC, ELN, EPL), la formación de los grupos paramilitares y sus cambios a través del tiempo, las desmovilizaciones de algunos grupos guerrilleros y la dinámica actual del conflicto armado.

Durante este periodo, Colombia ha vivido la degradación de la guerra, fruto de la cual, ha tenido que afrontar el desplazamiento de poblaciones enteras, el despojo y la expropiación de tierras, los asesinatos sistemáticos de líderes y lideresas, la desaparición de partidos políticos, la desaparición forzada, los crímenes de Estado, las masacres, torturas, reclutamiento y violencia sexual contra los civiles, la violación de los Derechos Humanos y del Derecho Internacional Humanitario y el ataque a las comunidades negras e indígenas. Todo esto ha venido acompañado de problemas estructurales que han intensificado el daño del Estado colombiano - como la pobreza, la desigualdad, la corrupción, la violación de los derechos básicos, el clientelismo, entre otros- y han hecho más difícil la superación del conflicto.

Se debe que aclarar que la violencia en Colombia tiene dinámicas diferenciadas a lo largo y ancho del territorio nacional, según el contexto, 
la época, la ubicación geoestratégica, los intereses regionales, las autoridades locales y los intereses económicos. Por lo tanto, no se puede afirmar que, en el caso de la violencia sexual contra el hombre, esta sea una estrategia de guerra utilizada en todos los lugares del país, ya que eso depende de qué tipo de actor hace presencia, por qué está en determinada zona, qué tipo de presencia ejerce, etc.

En cuanto a las cifras reportadas por varias instituciones como Medicina Legal, Fiscalía y Unidad de Víctimas, estas no muestran un consenso sobre la problemática ni permiten trazar tendencias, pero sí posibilitan un acercamiento a estas. En Medicina Legal, por ejemplo, los casos se registran a través de los exámenes medicolegales, en los cuales se puede ver: 1) la falta de información o categorización de los casos en relación con el conflicto armado hasta el 2004; es decir que, antes de este año, las denuncias por delitos sexuales se clasificaban por padre, padrastro, conyugue, familiar, otro conocido y desconocido, en las que probablemente se encontraban algunas situaciones de conflicto armado. 2) Las cifras más altas reportadas de violencia sexual contra hombres se ubican entre los años 2005 y 2009; es posible determinar esto debido al aumento en los análisis sobre violencia sexual a nivel nacional, que trazan una intención clara de visibilizar el problema a nivel institucional. 3) El mayor victimario, según los datos, son las Fuerzas Armadas de Colombia con 223 reportes, seguido de grupos paramilitares y bandas criminales con 91 reportes. En total, desde el año 2004 hasta el 2016, se reportan 373 casos. Y desde el 2004 hacia atrás, no se tienen cifras.

La Unidad de Víctimas, por su parte, a través del Registro Único de las Víctimas, ha consolidado un registro desde 1985 hasta el 2017. El número de hombres víctimas de delitos contra la libertad y la integridad sexual, para enero del 2018, es de 1863. Adicionalmente, se reportan 592 personas víctimas de este delito, cuya categoría en las tablas de datos es "no informa". Por lo tanto, se presume que dentro de esta categoría se pueden encontrar algunos casos más de hombres. 
Respecto a la tortura, las cifras aumentan notoriamente, ya que se reportan 6095 hombres víctimas. Sin embargo, no es posible saber si dentro de la tortura existió algún tipo de violencia sexual contra ellos. Tampoco se puede saber a ciencia cierta qué tipo de violencia sufrió y por parte de qué actor. No obstante, la información guarda un nivel de detalle importante en la medida en que determina el lugar de ocurrencia, año, género, ciclo vital y pertenencia a grupo étnico. Según la información reportada, en el año de 1984 se registraron 88 casos, una de las cifras más altas en el periodo que cubre dicha unidad. Luego, se identifica un aumento entre los años 1995 y 2005, entre los cuales el 2002 es el año con más reportes sobre estas agresiones. Los departamentos en donde más se han identificado estos casos son Antioquia (162), Magdalena (148), Bolívar (68) y Cauca (68), zonas de alta conflictividad y presencia de varios actores armados.

Como se puede observar, las cifras son notoriamente inferiores en comparación con las de las mujeres, razón por la cual, muchos de los argumentos ofrecidos ante la negativa de analizar el caso de los hombres apuntan a su poca representatividad en términos cuantitativos. No obstante, es importante tener en cuenta tres elementos: el primero es el problema que implica el subregistro; el segundo, ligado al anterior, es la falsa relación que suele hacerse entre denuncia con número de hechos y, por ende, la tendencia a percibir la violencia sexual con base dicho número. Como bien dice el informe de Medicina Legal (2002): "Frecuentemente se tiende a medir o a percibir la violencia según el número de hechos medidos y reportados, sin embargo, estos indicadores pueden no dejar percibir algunas realidades de la violencia y específicamente de la agresión sexual” (p. 3). El tercero es la poca claridad que se tiene sobre la tortura y la violencia sexual contra los hombres, lo que conlleva la alta probabilidad de que, dentro de las cifras de tortura, se puedan encontrar casos de violencia sexual no reportados como tal.

Ahora bien, se puede afirmar, a partir del análisis y caracterización de los casos, que en las zonas donde han sucedido, los objetivos han sido: 
1) minar a las comunidades a través de la agresión hacia sus autoridades y líderes hombres; 2) adquirir información mediante la tortura, dentro de la cual se encuentra la violencia sexual, por lo general con tipologías como la amenaza a ser violado o a quedar estéril o el maltrato de los genitales; 3) el castigo por ser colaborador de la guerrilla, por ser guerrillero o por llevar acciones en contra de los intereses del grupo armado, expresado en actos como la violación, la mutilación y la exposición degradante del cuerpo de la víctima (empalamiento, genitales en su boca, posiciones sexuales), como se ha visto en la entrevistas practicadas a los habitantes del Chocó.

Además, a partir de la caracterización de $226 \operatorname{casos}^{4}$ analizados para la presente investigación, se pudieron identificar varios elementos importantes a la hora de comprender la violencia sexual contra el hombre en Colombia como el uso de este tipo de violencia, la tipología y los victimarios. Cabe anotar que, algunos registros no poseen nombre de la víctima ni lugar de ocurrencia, pues cuando se trata de este tema, la denuncia conlleva, generalmente, el anonimato, por varias razones: una de ellas tiene que ver con los sentimientos de vergüenza, impotencia y confusión que generan estos hechos (Fuchs, 2004, p. 98); seguida de la alta probabilidad de ser estigmatizados y considerados homosexuales (mancha homosexual o estigma antigay) (Sivakumarán, 2005, pp. 12851288) o asegurar que eran merecedores de este tipo de agresiones (Kramer, 2006, pp. 295-300). Otra situación común es la incredulidad frente a la narración tanto por parte de su comunidad como de las entidades correspondientes; además, se corre un gran riesgo al denunciar; y, final-

4 No se pudo comprobar si los 226 casos caracterizados a lo largo de la investigación hacen parte de las estadísticas de Medicina Legal o Unidad de Víctimas, ya que, por razones de seguridad, los datos personales de las víctimas no son de acceso público. Estos casos se reconstruyeron a partir de diferentes fuentes. Desde 1990 hasta el 2017 se reunieron narraciones recopiladas en la Revista Noche y Niebla, Justicia y Paz del Banco de Datos del Cinep y las sentencias de paramilitares acogidos a Justicia y Paz. Adicionalmente, se encontraron algunos casos en el archivo de prensa consultado desde 1991 hasta el 2017. Desde 1950 hasta 1980, se reunieron casos narrados en El libro negro de la represión. 
mente, muchas de las víctimas son asesinadas, así que su registro no es directo o muchas veces no existe.

En razón a la dificultad que genera la narración de estos hechos, uno de los hombres víctimas de violación cuenta:

Creo que era martes, como a las seis de la tarde. Yo tenía 46 años. Fue el 2 de febrero del 2006, eso no se me olvidará. En la escuela había como una granjita, y yo les dije que sí, que pasaran y cogieran las mandarinas. Se sentaron un rato y ahí fue cuando me puse nervioso. Cuando empezaba a anochecer les dije que me tenía que ir a dormir, que si querían se podían quedar un rato y coger más frutas. El más viejo me dijo que cuál era el afán, que estaba muy temprano, y se miraban entre los dos y se reían. Yo rezaba, le rogaba a Dios que se fueran; de un momento a otro el grande me dijo que entráramos en la habitación.

Yo le dije que me respetara, que como así, que era un docente con esposa y con hijos, el profesor del pueblo. Que merecía respeto. Me asusté y me puse a llorar. Me dijeron 'nenita, no llore', y el más grande me empujó. El tipo me bajó los pantalones y me puso el arma en la cabeza. Grité pero por ahí no hay nada cerca, y ni me salía la voz. Cuando terminó, entró el otro. Me dijeron que cuidado avisaba a alguien, que no hiciera ningún comentario. Sangré mucho, lloré toda la noche, tirado ahí en la cama, solo. Al día siguiente tuve que hacer como si nada y recibir a los niños. A los ocho días me llené de llagas, no aguantaba el dolor, el ano se me inflamó; desesperado le pedí ayuda a una vecina, le dije que me acompañara al médico, que me había bañado con agua sucia.

El médico que me revisó me preguntó si me habían violado. Yo le dije que no; me daba vergüenza. Le dije que había sido el agua sucia de la vereda. Una vez me puse muy mal y creí que estaba contagiado de sida.

Le conté a una de mis hijas; mi mujer se enteró y ya no me miró igual. Al cabo de un tiempo nos separamos, porque ella me rechazó. Veinte años de 
casados se acabaron por culpa de lo que me sucedió. Imagínese que me acusó de haberlo provocado. ¡Cómo se le ocurre! Aunque sí dudé. ¿Será que ellos creyeron que era homosexual? Yo le dije a mi mujer que si hubiera sido gay no me habría casado con ella ni habríamos tenido hijos. Pobrecita, en el fondo la entiendo; ella no tiene estudios, estas cosas no las comprende. Por eso fue que nunca me apoyó.

Me sentía chiquitico, con la autoestima destrozada. Vivía aterrado, no podía hablar delante de otros profesores ni de los padres de familia, pensaba que se me iba a notar, que se iban a dar cuenta de que dos tipos me violaron. Qué vergüenza que se enteraran. Ahora estoy mejor, aunque todavía me da miedo que alguien lo sepa, me da miedo que la gente vaya a pensar que soy homosexual, porque no lo soy. (Escarraga, 2014)

En cuanto a la estigmatización y su relación con la homosexualidad, se resalta el caso de un hombre que denunció haber sido violado, pero las personas competentes para registrar su denuncia, al no saber en qué categoría ubicarlo, registraron su caso dentro de los de la población LGTBI, acción que, de entrada, causa un alejamiento inmediato de la víctima e impide su posterior tratamiento (Carolina Tejada, 2017).

Finalmente, frente a la relación entre la violación de un hombre y su suicidio, María Emma Wills dice que:

En Colombia este fenómeno no se ha explorado lo suficiente. Sus investigaciones de campo, eso sí, le permiten inferir que estamos ante un escenario aterrador: "Hicimos un trabajo sobre violencia sexual en los Montes de María, Magdalena y La Guajira. Tan solo encontramos dos casos de hombres en el Magdalena, pero no hay testimonios directos porque ambos se suicidaron. No pudimos hablar con sus familiares”. (Wills citada en Escárraga, 2014)

De igual manera, Carolina Tejada (2017) narra un caso en el que un hombre fue violado $y$, al pensar que alguien se había enterado de su situación, se suicidó. Este elemento es muy importante, ya que el 
suicidio hace parte de los aspectos menos estudiados en el conflicto armado y es una de las causas por las cuales no se da razón de cifras más sólidas sobre la violencia sexual contra el hombre.

\section{Usos de la violencia sexual}

Al analizar cada una de las 226 narraciones, es claro que el uso de este tipo de violencia en los hombres tiene diversos objetivos. Está lejos de ser una acción llevada a cabo por un deseo físico del victimario. Eso quiere decir que, pensar que quien abusa sexualmente de un hombre tiene necesariamente una orientación sexual diversa, es errado, pues esconde la dinámica por excelencia de esta acción, que es la manifestación de dominio y poder sobre el otro (Kramer, 1998, pp. 311-315; Javaid, 2016, p. 284). Además, como dice Groth y Burgues (1998), cada agresión sexual realza la masculinidad del agresor y minimiza la de las víctimas, por tal razón, este tipo de situaciones termina convirtiéndose en un escenario de burla de parte de los victimarios.

Según los datos recopilados, se pudieron identificar cuatro razones por las cuales se cometió violencia sexual (entre maltratos, amenazas, violación y mutilación). La adquisición de información; el castigo por pertenecer, según el agresor, a un grupo armado determinado o por auxiliarlos; la reducción de la autoridad y el liderazgo ante a una comunidad (Ruth Graham, 2006); y la demostración de la presencia, superioridad y dominio del actor armado frente a las comunidades.

En el caso de la adquisición de información, la violencia sexual ocurre dentro de la tortura. Los casos reconstruidos muestran que, por ejemplo, en la época de Turbay Ayala, con el Estatuto de Seguridad, la modalidad que más se denunciaba eran los golpes y choques eléctricos a genitales, acompañados de insultos y amenazas de tipo sexual. Adicionalmente, los victimarios que se reportaban con mayor frecuencia eran los militares y policías. Esto se debe a que la violencia sexual estaba enmarcada dentro de la tortura a la que era sometida la mayoría de 
hombres detenidos. Según la caracterización de los casos registrados para esta investigación, de 42 casos, 33 presentan golpes, choques, maltratos en los testículos y amenazas de dejarlo estéril o castrarlo (base de datos propia).

Aquí, la violencia sexual ocurre en un escenario privado - como se caracteriza a la tortura-, como lo muestra el siguiente caso ocurrido en Palmira, Valle del Cauca, en 1979: “Me cogieron y me llevaron a varios lugares donde me pegaron, luego de esto me amarraron en un asiento metálico y sujetado por dos torturadores y me decían, te vamos a dejar estéril empezaron a ponerme cables en los testículos" (El libro negro, p. 297). Cabe aclarar que este tipo de hechos se dieron tanto en el escenario urbano como en el rural y, a pesar de que en esta época se pone en evidencia este tipo de hechos por parte del Estado, la tortura y la violencia sexual dentro de la misma han sido comunes desde los años cincuenta (Aranguren, 2016, pp. 169-170).

En cuanto a la violación, esta también se llevaba a cabo, aunque no era tan común, pero siempre estaba dentro de un escenario de tortura, cuyo fin era la adquisición de información y la eliminación de lo que se consideraba diferente dentro de la dinámica de la doctrina de seguridad nacional. Uno de los casos narra: “[...] tres noches seguidas fui torturado. [...] En una de ellas, mientras estaba colgado, trataron de introducirme un palo en el ano; me alcanzaron a romper los pantaloncillos y a lastimarme [...] (pp. 173-174). Como una de las formas de tortura, este tipo de tratamientos cumplen una función importante, ya que, gracias al miedo que genera la amenaza de ser castrado ("menos hombre”), quedar estéril ("menos hombre"), aunada al dolor, los victimarios han aprovechado para adquirir información o inducir respuestas, aunque no sean ciertas.

También se ven casos similares en el contexto del conflicto armado a partir de los años noventa, pero estos ya no se enmarcan dentro de una dinámica de detenciones avaladas por el Estado, así que no son tan 
comunes y no son practicadas únicamente por las Fuerzas Militares, sino también por los grupos alzados en armas, tanto las guerrillas como los paramilitares, estos últimos con mayor frecuencia.

En el año 2007, encontramos en Convención, Santander:

El señor, cuando se desplazaba por un camino de la inspección de Policía San José de Las Pitas (Convención), fue interceptado por tropas de una brigada móvil, quienes lo sometieron a tortura psicológica. Los militares le decían que: "lo iban a castrar y a arrancar las uñas y que tenía que cavar un hueco, donde iba a quedar enterrado”. (Noche y Niebla, p. 35)

En el sur del Cesar, en 1994:

Varios hombres armados que vestían prendas militares de camuflaje y estaban fuertemente armados, abordaron a Manuel cuando se dirigía de la vereda El Diviso hacia San Martín. Los individuos obligaron a Manuel a abordar una camioneta Chevrolet color azul, en la cual se movilizaban, luego partieron con rumbo desconocido. Al marcharse, uno de los desconocidos se fue en la motocicleta siguiendo el vehículo. El cuerpo de Manuel fue encontrado el 23 de septiembre de 1994 enterrado en La Granja de propiedad del señor Ramiro Manzano, ubicada a 10 kilómetros del casco urbano de San Martín. El informe de necropsia permitió establecer que Manuel había sido torturado y asesinado el mismo día de su retención. A Manuel Guillermo le quitaron las uñas, le cortaron las orejas y la nariz, le cercenaron el pene, le abrieron los testículos, le cortaron el ano y su cuerpo estaba maniatado. (Nunca Más Colombia)

A partir de los años noventa, la violencia sexual suele ser más usada como forma de castigo y se recurre, además, a la mutilación, maltrato y violación. Algunas de estas acciones ocurren en público o exponen el cuerpo maltratado en público, pues no solo se trata de "castigar" al supuesto culpable, sino de darle un mensaje a su familia, a su comunidad o a su grupo, a través del exceso, como una forma de teatralizar la 
violencia. Desde entonces, estas formas de violencia sexual se vuelven más comunes y la dinámica del conflicto cambia notoriamente. Ya no se habla de un entorno de tortura en el que el Estado está seriamente comprometido, sino de actores armados diversos que entran en la dinámica de disputa y control territorial, por lo cual, el castigo y la conquista de territorios se vuelve fundamental.

El exceso en todas las formas de agresión y la exposición pública de los actos se vuelven comunes y con ello la trasmisión de mensajes por medio del cuerpo sufrido, del cuerpo herido y mutilado, como puede verse en los siguientes casos ocurridos en Simití Bolívar, Tarazá Antioquia y Magdalena Medio:

- El tío de las víctimas, en entrevista de Policía Judicial del 8 de marzo de 2011, manifestó que sus sobrinos y un trabajador de ellos fueron interceptados por paramilitares del Bloque Mineros. Según comentó un señor vecino, quien ya falleció, él iba con unas mulas y observó cuando los paramilitares, entre los que se encontraba alias Carecrimen, los mataron a machetazos e incluso este lo amenazó para que se devolviera o hacía lo mismo con él. Indicó también que, según otra versión que le contó el señor Espinoza, le habían arrancado el pene y se lo habían puesto en la boca, y los habían asesinado a dos cuadras de la Clínica del Guáimaro, en un filo y luego los descuartizaron (Sentencia del Bloque Minero, p. 1110).

- Simití (Sur de Bolívar), un hombre de 33 años fue violado por cinco integrantes de las nuevas bandas. Padre de dos hijos, fue amarrado a un árbol y humillado por sujetos que le dijeron que eso le pasaba por ser de la guerrilla (El Tiempo.com., 12 de diciembre del 2009).

- Un campesino fue detenido y desaparecido el 5 de noviembre junto con su esposa de veinte años que, además, fue torturada y amenazada por efectivos de una brigada móvil. Los militares llegaron hasta la casa de la pareja y su niño de cuatro meses y comenzaron a maltratarlos. Los campesinos fueron golpeados mientras les preguntaban por la guerrilla. Al no obtener ninguna respuesta 
satisfactoria, los uniformados decidieron, por orden del oficial al mando, ultrajar sexualmente a Hugo introduciéndole en el ano el cañón del fusil (Nunca Más Colombia).

En estas situaciones, el castigo a través de la violencia sexual feminiza al hombre (Freivogel, 2010; Lewis, 2009; Ruvinsky, 2012), lo homosexualiza (Ferrales, Noyseth y Mcelrath, 2016) o lo castra, lo que significa, en la sociedad, que se hace menos hombre mediante la humillación y la agresión a su masculinidad.

Respecto al interés por minar la autoridad y el liderazgo en las comunidades, cada caso que aquí se muestra da cuenta de la reducción practicada a la víctima y, con esto, a su rol dentro de la familia, grupo o comunidad. La violencia sexual, como se ha dicho permanentemente, tiene construida la figura del hombre con unas características propias que lo relacionan con la fuerza, la autoridad y el liderazgo. Las masculinidades diferenciadas y establecidas en cada región cumplen un papel muy importante, por lo tanto, es muy común que un hombre violentado sexualmente pierda el apoyo y el respeto del grupo que lo rodea, de su familia o de la comunidad que representa, ya que su masculinidad ha sido puesta en duda:

- Tortura del dirigente del Comité Veredal de Usuarios Campesinos. Seis policías lo amarran del cuello a un poste y le golpean los testículos (El libro negro de la represión, p. 121).

- Dos hombres fueron asesinados, cuatro hombres y una joven fueron desaparecidos y ocho líderes comunitarios fueron violados sexualmente, durante una acción conjunta entre miembros de un batallón militar y paramilitares en el corregimiento Pueblito Mejía de Barranco de Loba (Movimiento de Víctimas, Movice).

- Los usuarios campesinos de Córdoba denuncian torturas. El comité femenino de usuarios de Chuchurubí denuncia torturas a 33 campesinos: "los carabineros se los pararon sobre el vientre y las cabezas; punta pies en la cara y el cráneo; impedirles satisfacer sus necesidades fisiológicas; impedirles el reposo nocturno; mantenerlos a la 
intemperie todo el día, desnudos y sin comida; cuando pedían agua, se les orinaban encima”. Se denuncian los hechos ante la Cruz Roja Nacional (El libro negro de la represión, p. 152).

A propósito de las masculinidades y el ataque directo que representa la violencia sexual contra ellas, cuando se pregunta por este tipo de hechos en los hombres, algunas mujeres y hombres, por lo menos en el departamento del Chocó, dicen que el hombre es una figura de autoridad, de poderío y de liderazgo. Esto implica que, una victimización de este tipo, como lo dice la población, pueda alterar las figuras de autoridad de la comunidad y produzca vergüenza.

Al respecto, dicen varios habitantes:

Si un hombre es violado o agredido sexualmente, afectaría a la comunidad en general, teniendo en cuenta que no es una sola comunidad, sino somos unidas y cualquier cosa que suceda en una comunidad va a afectar a toda la comunidad y si es a una persona mucho más. Y, si es un líder, afecta como a esa persona, como a su familia, como a su comunidad en general (Entrevista a mujer, municipio de Chocó, septiembre 2014).

Ya su autoestima frente a la sociedad y a la comunidad no va a ser la misma, pueda que esa persona se afecte psicológicamente, ya no se reúna como antes con las otras personas, ya esa persona no va a tener esa expectativa de que él era el jefe y ya no se va a poder dirigir hacia las otras personas, le van a dañar la reputación (Entrevista a hombre, municipio de Chocó, septiembre 2014).

Si un hombre se violenta y tiene, por decir, un cargo alto, eso sería una vergüenza para toda la comunidad y para el mismo hombre, si es una persona que es muy poco visible, nosotros decimos pobrecito, qué pecao, le pasó a él, pero en mis formas de ver las cosas, eso, si pasa en la comunidad, me llenaría a mí de odio, de ira de haber personas que son capaces de hacer tales actos, porque, a pesar de todo, nosotros somos libres y nadie tiene derecho a tocar el cuerpo de nadie porque somos libres, nacimos libre y como tal debemos estar (Entrevista a hombre, municipio de Chocó, septiembre 2014). 
De igual forma, comentan el caso de un joven con problemas de retraso, quien en la noche fue acosado y violado por personas, aún son desconocidas; sin embargo, algunos consideran que fue responsabilidad de actores armados, ya que son los únicos que transitan a altas horas de la noche, como se expresa a continuación:

Era un muchacho muy sociable, esa noche lo convidaron a beber trago y creo que entre dos o tres jóvenes lo violaron, el muchacho hasta ahora tiene problemas, lo han llevado aquí al hospital y también lo han llevado afuera, pero sigue con la dificultad, sigue con problemas. Pero ya no lo veo en la calle porque era como un personaje en el municipio. Y yo estoy seguro que las personas no son personas de acá, pueden ser personas de grupos al margen de la ley, porque después de una hora ninguno de nosotros salimos, ni tomamos, ni nada, solo ellos pueden hacerlo (Entrevista, municipio de Chocó, septiembre 2014).

Finalmente, el establecimiento de un grupo armado en algunas zonas se manifiesta con masacres, torturas, asesinatos selectivos o no, lo cual reafirma su presencia y su dominio. La violencia sexual también hace parte de estos rituales, en su mayoría con mutilaciones, seguidas del asesinato $\mathrm{y}$, finalmente, la ubicación del cuerpo en posiciones que ridiculizan a la víctima.

En un municipio ubicado en el Chocó, la llegada de los grupos paramilitares estuvo acompañada del asesinato de líderes hombres, cuyos cuerpos fueron encontrados en posiciones sexuales y sus órganos genitales en la boca. Según una de las mujeres entrevistadas, "los paramilitares llegaron, mataron a muchos hombres que eran líderes, les cortaron los testículos y se los pusieron en la boca, para que dejaran de ser sapos" (Entrevista, municipio de Chocó, septiembre 2014).

Otra mujer entrevistada comenta:

Se decía que cuando llegaron los paramilitares, mataban a los hombres, los ponían acurrucados y con los testículos en la boca. También mataron a un líder y lo empalaron. Lo dejaron empalado y sin pantalones (Entrevista, municipio de Chocó, septiembre 24 2014). 
Cuando el conflicto era mucho más fuerte, se podían encontrar hombres asesinados con el pene en la boca. Son historias que he escuchado, era muy pequeña cuando llegó la violencia en 1996, muchos hombres, algunos los mataron y cuentan, cuentan que los asesinaban y fuera de eso les mochaban el pene y se lo colocaban en la boca, y que cigarrillos, son historias muy tristes.

También a algunos los trataban de maricas y que tenían que hacer lo que ellos decían, si no lo hacían, eran considerados menos hombres. (Entrevista, municipio de Chocó, septiembre 2014)

Este tipo de hechos, no solo contra el cuerpo vivo, sino contra el cuerpo sin vida y víctima de agresiones con connotaciones sexuales, es una forma de matar y contramatar a la víctima, de quitar su vida y de matar lo que representa en la sociedad, de deshumanizarlo en su máxima expresión y de convertirlo en un cuerpo que comunica a través del exceso. Como dice Blair (2005) el cuerpo muerto es donde ocurren las violencias, es en él y a través de él en donde la violencia habla y comunica (p. 47).

Con base en los casos reconstruidos, el número de víctimas por año y por departamento se reporta así:

\section{Gráfica 1. Número de víctimas hombres por año 1964-2017.}

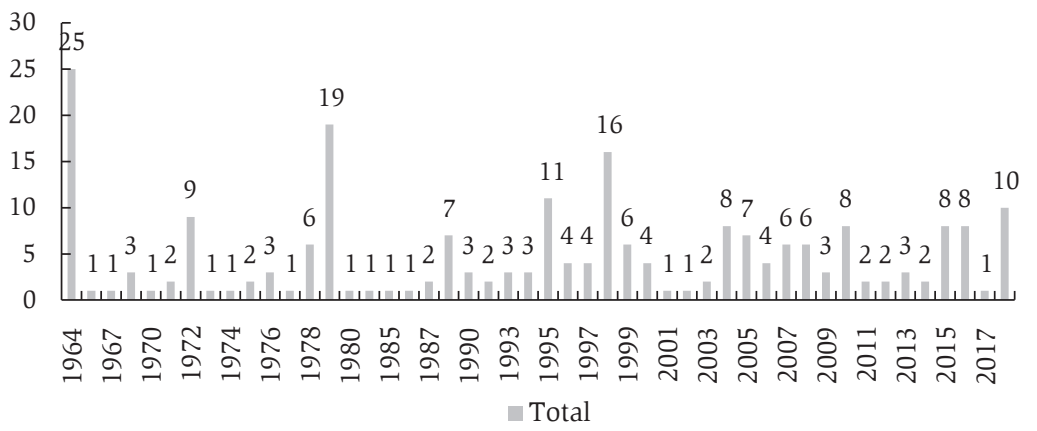

Fuente: Elaboración propia 
Tabla 1. Número de víctimas por departamento

\begin{tabular}{|c|c|c|c|}
\hline Departamento & n. ${ }^{\circ}$ & Departamento & n. ${ }^{\circ}$ \\
\hline Antioquia & 19 & Cundinamarca & 1 \\
\hline Arauca & 2 & Huila & 8 \\
\hline Atlántico & 3 & Magdalena & 9 \\
\hline Bogotá & 27 & Meta & 13 \\
\hline Bolívar & 17 & Nariño & 2 \\
\hline Boyacá & 1 & Norte de Santander & 16 \\
\hline Caldas & 24 & Putumayo & 2 \\
\hline Caquetá & 7 & Quindío & 2 \\
\hline Casanare & 2 & Risaralda & 1 \\
\hline Cauca & 2 & Santander & 22 \\
\hline Cesar & 10 & Sin dato & 10 \\
\hline Chocó & 2 & Tolima & 1 \\
\hline Córdoba & 8 & Valle del Cauca & 15 \\
\hline
\end{tabular}

Total: 226

Fuente: Elaboración propia

\section{Tipo de violencia sexual y victimarios}

Dentro de la violencia sexual perpetrada en Colombia contra los hombres, son cinco modalidades las más utilizadas. La mutilación de genitales, el maltrato a genitales, la amenaza a ser violado o a quedar estéril, la violación y el desnudo. Por lo general, cada una de ellas se ubica en determinados contextos, como se ha explicado anteriormente. Por ejemplo, la mutilación, que es utilizada antes de asesinar al hombre, puede ocurrir durante un interrogatorio o captura. En la base de datos, se pudo identificar que muchos de los hombres que eran capturados en tomas paramilitares eran mutilados antes de ser asesinados. También 
se encontró el caso de un miembro de las FARC que es acusada de mutilar a varios hombres, como muestra la siguiente narración, ocurrida en el año 2000:

Relató que mientras se dirigía con su familia a bordo de un bus de transporte público entre Chigorodó y Mutata, cayeron en un retén de las FARC comandado por esa jefe guerrillera. El grupo delincuencial, que según Páez Ramos es integrado en su mayoría por menores de edad entre los nueve y quince años, le cercenó de un disparo sus genitales y pene, por el hecho de portar libreta militar de primera clase y negarse a integrar el grupo guerrillero que comandaba. Miguel Antonio Páez, un expolicía, quien había prestado el servicio militar obligatorio, dijo que esas condiciones fueron atractivas para alias "Karina”, quien, al darse cuenta de que él no quería irse, decidió dispararle a sus partes íntimas y lo dejó por muerto. Agregó que, a los otros hombres con su misma condición, la guerrillera procedió, "cuchillo en mano, a córtales sus penes y testículos hasta dejarlos desangrar y, consecuentemente, morir mientras a otros los remató con tiro de gracia”. (Caracol Radio, 4 de octubre 2008)

Esta mutilación implica una reducción total de la masculinidad de la víctima no solo por la castración, sino por las consecuencias que acarrea como la pérdida de su familia y pareja, la imposibilidad de tener hijos en el futuro y el cuestionamiento de su identidad como "hombre", dentro de los parámetros de su cultura.

El maltrato a genitales y la amenaza son modalidades usadas, sobre todo, en interrogatorios acompañados por otro tipo de agresiones. Dentro del maltrato, están los golpes, las punzadas, las quemaduras y choques eléctricos. Uno de los informes de la Comisión de Torturas, presentando el 31 de marzo de 1971, en el marco del Foro por los Derechos Humanos, expone diferentes testimonios y cartas que demuestran un orden estipulado en las torturas establecidas en los interrogatorios practicados por las Fuerzas Armadas en Colombia, que incluyen las agresiones a las partes íntimas (El libro negro de la represión, pp. 237-238). 
Como se dijo anteriormente, el objetivo aquí era lograr adquirir información y castigar a quienes determinaba la justicia militar. Se trata, entonces, de generar la mayor cantidad de dolor en el cuerpo, especialmente en las zonas que, además de ser sensibles al dolor, son un componente definitivo en la identidad de género de la víctima.

Ahora bien, el desnudo se utiliza en todos los escenarios, tanto en los de interrogatorio, como en capturas, castigos y amedrentamientos. En algunos casos, han llegado a fotografiar a los hombres con el fin de causar miedo y terror. En otros, lo usan como especie de castigo o presión al hacerlos desnudar y abandonarlos en lugares fríos y húmedos, como lo registra Noche y Niebla en uno de sus reportes:

- El 9 de junio, en la vereda Bella Unión (Honduras), miembros del Ejército hicieron desnudar a un campesino y le tomaron fotografías por todos lados, además de someterlo a un interrogatorio.

Finalmente, la violación se ve en escenarios en donde el castigo es una de las principales motivaciones. Ya no es tan común en los interrogatorios como sí lo es en las capturas por ser acusado de auxiliar o de pertenecer a un grupo armado legal o ilegal o por liderar causas sociales, como sucedió con el miembro de Sintraemposan:

- Un obrero de la Empresa de Obras Sanitarias de Santander, Emposan S. A., tesorero de Sintraemposan y militante de A Luchar, fue desaparecido y asesinado en Barrancabermeja. El obrero se dirigía en motocicleta hacia el barrio Cincuentenario a realizar sus labores habituales de trabajo cuando fue interceptado por cuatro individuos armados con ametralladoras quienes se movilizaban en un vehículo y se lo llevaron a la fuerza, dejando la motocicleta en el sitio de su rapto. Se recibieron llamadas telefónicas, por medio de las cuales el grupo paramilitar MAS se adjudicaba los hechos y expresaban que entregarían a Gerardo muerto en las próximas horas. Su cadáver fue encontrado semienterrado en el sitio Campo n. ${ }^{\circ} 45$, pozo de explotación petrolera, dentro de un área restringida, ubicado en el corregimiento El Centro; el cuerpo presentó muestras graves de tortura: amarrado de pies y manos con alambre de púas, las uñas arrancadas, la cabeza sin cabello, un brazo partido al parecer con machete, 
heridas con cuchillo, una varilla introducida en el recto, sus testículos arrancados, lo ahorcaron y le propinaron varios impactos de bala. En la espalda del cadáver de Gerardo aparecieron las letras cccc, Comando Coronel Correa Campos, organización paramilitar formada luego de la muerte de dicho coronel (Nunca Más).

- Ingresaron a la residencia del señor y luego de agredir a todos los que estaban presentes y apropiarse de bienes muebles y enseres, procedieron a accederlo carnalmente mediante violencia, como represalia porque, supuestamente, en el lugar se escondían armas de la subversión (Sentencia del Bloque Norte).

- Llegaron cuarenta miembros aproximadamente del grupo paramilitar. Rafael se encontraba laborando como jornalero, a quien procedieron a atar y colocarle una bolsa plástica en la cabeza, interrogándolo sobre que otro grupo armado había pasado por ese sector. Seguidamente, lo golpearon con la rama de un árbol de espinas en la espalda, con las armas de fuego en la cabeza y fue accedido carnalmente por dos de los integrantes de ese grupo armado ilegal, diciéndole que eso le pasaba por encubrir a otras personas. Como consecuencia de estos hechos, se desplazó de manera forzada de la localidad (Sentencia del Bloque Norte, p. 524).

\section{Gráfica 2. Número de casos por tipo de violencia sexual.}

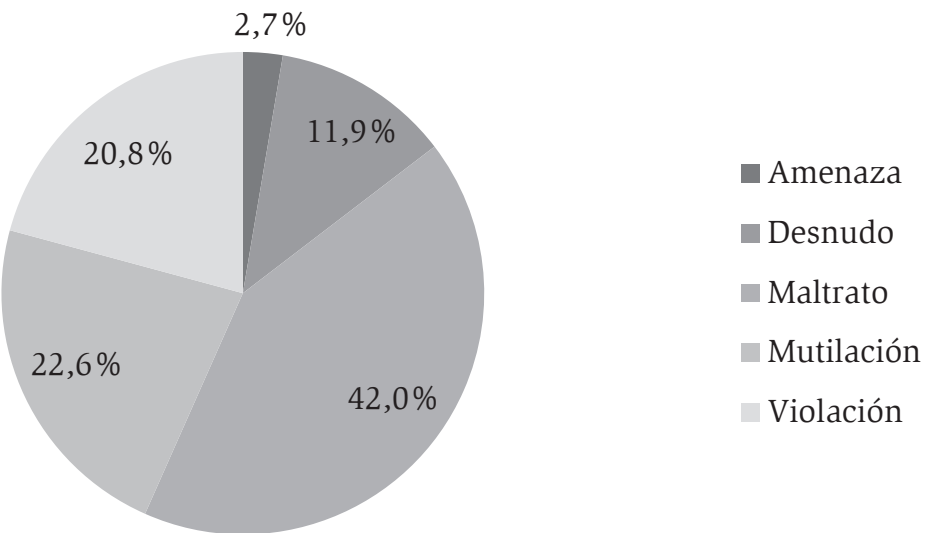


Finalmente, en cuanto a los victimarios, de los 226 registros, se encontró que la mayoría de los hechos fueron perpetrados por las Fuerzas Armadas, seguido de paramilitares, y, por último, miembros de guerrilla. En los registros de Medicina Legal, el grupo que comete más actos de este tipo son también las Fuerzas Armadas.

Los periodos de mayor ocurrencia son los años 1964, 1979, 1988, 2005 y 2010. Estos datos pueden dar algunas luces sobre la violencia sexual contra hombres, aunque no pueden exponer tendencias, ya que los datos son escasos. No obstante, gracias a ellos se puede identificar que entre los años 1964 y 1979, el Estado de Sitio hizo posible que aumentaran las denuncias en los casos de tortura, dentro de la cual era recurrente la violencia sexual. Ahora bien, el hecho de que se reporten más casos en estos años no quiere decir que la tortura se haya implementado únicamente en esta época, sino que, como bien lo explica Aranguren (2016), las denuncias en contra de las Fuerzas Armadas —que tenían legitimidad para hacer detenciones e interrogatorios - aumentaron por un cambio de dinámica respecto a la tortura, la cual se empezó a llevar a cabo no solo en espacios rurales, sino urbanos (p. 178).

Posteriormente, a partir de finales de los ochenta y principios de los noventa, el conflicto cambia e involucra nuevos actores. Los paramilitares y las guerrillas entran en fuertes combates por el control territorial y una dinámica contrainsurgente liderada por grupos paramilitares se fortalece. Se incrementan las masacres, los asesinatos sistemáticos, la persecución y, con esto, también los actos de violencia sexual, sobre todo, contra las mujeres. Así mismo, se destaca un aumento de este tipo de violencia contra los hombres.

Varios informes de memoria histórica, onU Mujeres y Sisma mujer, registran que los grupos paramilitares utilizaron la violencia sexual como estrategia de guerra y, aunque en relación con los hombres no se registran tantos casos, se colige que ellos pudieron haber sido víctimas de un proceso similar. 


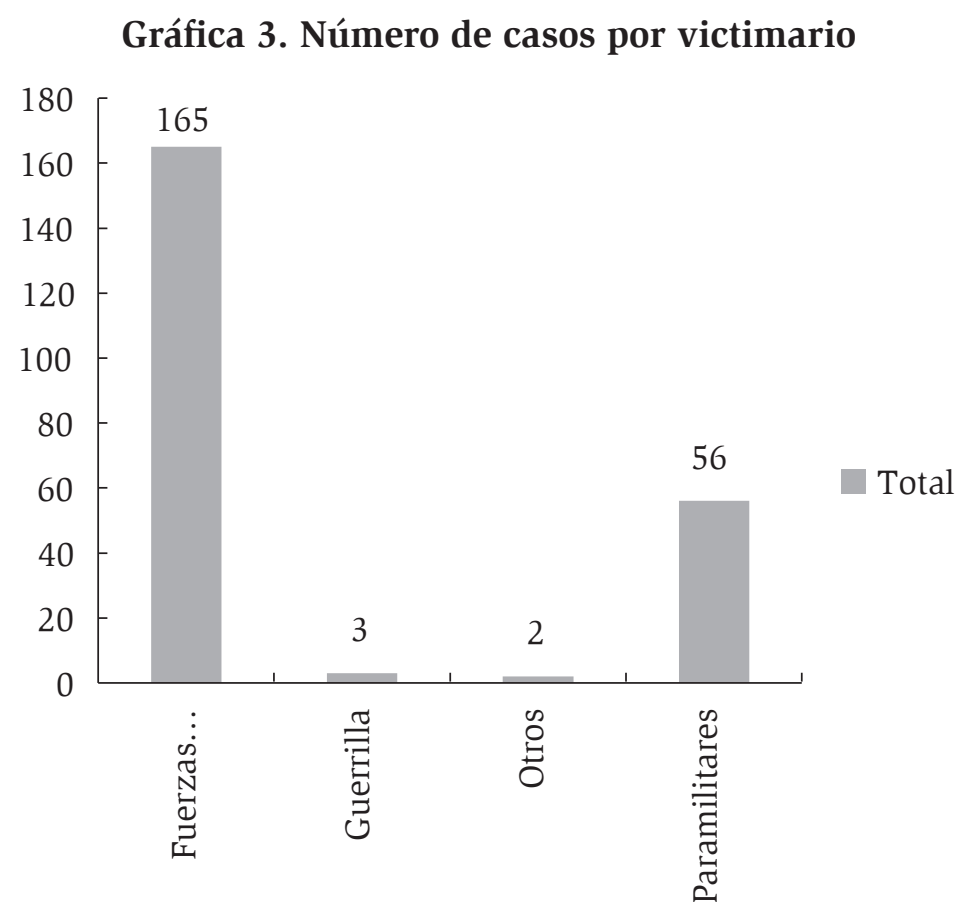

Fuente: Elaboración propia

\section{Conclusiones}

Esta breve aproximación a la violencia sexual contra el hombre, y la exposición de algunos casos de la caracterización de 226 en total, permiten resaltar cinco elementos claves a la hora de entender este tipo de violencia, por lo menos en Colombia:

1. El evidente desconocimiento de este tipo de violencia en los hombres y su desatención, producto de las exiguas denuncias, frente a lo cual, es importante tener en cuenta los factores que influyen en que el hombre no denuncie: la vergüenza, el miedo y la confusión, sumados a las escasas rutas ofrecidas para que el hombre relate sus experiencias y la tendencia a considerar que solo las mujeres son víctimas de esta violencia. Muchos de los hombres que han sido 
expuestos a este tipo de violencia, también lo han sido a otras torturas, que muchas veces han causado su muerte.

2. La posibilidad de caracterizar los casos demuestra que el tipo de violencia sexual que sufren los hombres es variado y que es más común de lo que se piensa. Al encontrar agresiones, mutilaciones y amenazas dentro de las denuncias de tortura, se genera la necesidad de revisar esta categoría y desmarcar la violencia sexual contra el hombre.

3. En Colombia, la violencia sexual contra el hombre ha sido utilizada como arma de guerra para diferentes objetivos: obtener información, amedrentar, castigar, minar a una comunidad a través de sus líderes y comunicar la consolidación de un grupo armado, a través de la feminización de la víctima, de la castración y de la homosexualización, que pretenden reducir su hombría. No obstante, esta no es la única motivación de aquellos que ejercen la violencia sexual en Colombia, pues, como se pudo evidenciar en cada caso registrado, el exceso en el trato de las víctimas y la crueldad impresa en el cuerpo de ellas permite también catalogar y explicar este tipo de hechos, que tienen como propósito, por un lado, generar el máximo dolor posible, y por el otro, convertir el horror en objeto de espectáculo, de desafío y de amenaza colectiva.

4. A pesar de tener cifras consolidadas en las diferentes instituciones como la Unidad de Víctimas y Medicina legal, es necesario generar estudios y análisis que permitan comprender la situación de los hombres y, de esta manera, conformar estrategias, rutas y metodologías para brindar atención y tratamiento. 


\section{Bibliografía}

Blair, Elsa (2001). El espectáculo del dolor, el sufrimiento y la crueldad. Controversia, segunda etapa, (178), pp. 84-99. Centro de Investigación y Educación Popular, Cinep.

Blair, Elsa (2005). Muertes violentas. La teatralización del exceso. Antioquia: Universidad de Antioquia.

Adam, Jones (2010). Gender and ethnic conflict in ex-Yugoslavia. Ethnic and Racial Studies, 1 (17), 115-134.

Aliraza, Javaid (2015). The dark side of men: the nature of masculinity and its uneasy relationship with male rape. Journal of Men Studies, 3 (23), 271292.

Aliraza, Javaid (2014). Male rape: the unseen world of male rape. Journal of Men Studies, 3 (23), pp. 1-42.

Aliraza, Javaid (2016). Feminism, masculinity and male rape: bringing male rape "out of the closet". Journal of Men Studies, 3 (23), 283-293.

Adam, Jones (2008) Gender and genocide. En Stone Dan (Ed.), The historiography of genocide. Reino Unido: Palgrave Macmillan.

Alison, Miranda (2007). Wartime sexual violence: women's human rights and questions of masculinity. Review of International Studies, 33, 75-90.

Aranguren, Juan Pablo (2016). Cuerpos al límite: tortura, subjetividad y memoria en Colombia (1977-1982). Colombia: Ediciones Uniandes.

Augusta, Del Zotto y Adam, Jones (2002). Maleon-male sexual violence in wartime: Human Rights' last taboo? Trabajo presentado en la Convención Anual de la International Studies Association. Recuperado de: https://bit. ly/2EQMah1

Carpenter, Charle (2006). Recognizing gender-based violence against civilian men and boys in conflict situations. Security Dialogue, 1 (37), 83-103.

Connell, Raewyn (1995). Masculinities. Cambridge: Polity Press.

Davies, Michelle y Rogers, Paul (2006). Perceptions of male victims in depicted sexual assaults: a review of the literature. Aggression and Violent Behavior $11,367-377$. 
Jones, Anthony y Fay, George (2004). Executive Summary Investigation of Intelligence Activities At Abu Ghraib. Army Publicy Affairs: Washington D.C.

Ferrales, Gabrielle; Nyseth Brehm; Hollie y Mcelrath, Sucy (2016), Gender and society, 4 (30), 565-589.

Graham, Ruth (2006). Male rape and the carefull construction of the male victim. Social \& Legal Studies, 15 (2), 186-208.

Henry, Nicola (2016). Theorizing wartime rape: deconstructing gender, sexuality, and violence. Gender and Society, 1 (30), 44-56.

Kahn Noreen, Abdullah (2008). Survivors of male rape: the emergence of a social and legal issue. Reino Unido: Palgrave Macmillan.

Kramer, Elizabeth (1998). When men are victims: applying rape shield laws to male same-sex rape. Law Review, 1 (7), 293-332.

Lees, Sue (2002). Carnal knowledge. Rape on trial. London: The Women's Press Ltd.

Lewis, Dustin (2009). Unrecognized victims: sexual violence against men in conflict settings under. International Law Wisconsin Journal of International Law, 1 (27), 1-49.

León, Magdalena y Viveros, Mara (Comps.) (1995). Género e identidad. Ensayos sobre lo femenino y lo masculino. Bogotá: Uniandes.

Philo Gorris, Ellen Anna (2015). Invisible victims? Where are male victims of conflict-related sexual violence in international law and policy? European Journal of women's Studies, 4 (22), 412-427.

Ruvinsky R., Elisya (2012). My heart bleeds, but where to take my grief is not there: 1 wartime sexual violence against men in the Balkan and Great Lakes regions. Tesis de maestría. Recuperada de: https://bit.ly/2Oe1d3K

Sandesh, Sivakumaran (2005) Male/Male rape and the 'taint' of homosexuality. Human Rights Quarterly, 4 (27), 1274-1306.

Sandesh, Sivakumaran (2007). Sexual violence against men in armed conflict. European Journal of International Law, 2 (18), 253-276. 
Sandesh, Sivakumaran (2010). Del dicho al hecho: la ONU y la violencia sexual contra hombres y niños durante conflictos armados. International Review of the Red Cross, 877, 1-20.

Stanko, Elizabeth (1995). Everyday violence: how women and men experience sexual and physical danger. Londres y San Francisco: Pandora.

Stemple, Lara (2009). Male rape and Human Rights. Hastings Law Journal, (60), 605-647.

Storr, Will (2011). The rape of men: the darkest secret of war. The Guardian. Recuperado de: https://bit.ly/2igjpOB .

Tarre Moser, Patricia y Leyva Morelos, Salvador (2015). Violencia sexual contra el hombre: avance jurisprudencial de la Corte Interamericana de Derechos Humanos. Revista Internacional de Derechos Humanos, 5 (5), 69-90.

Uribe, María Victoria (1978). Matar, rematar y contramatar. Las masacres de la Violencia en el Tolima 1948-1964. Controversia, 159-160.

Viveros, Mara (2001). Masculinidades. Diversidades regionales y cambios generacionales en Colombia: hombres e identidades de género. Investigaciones desde América Latina. Colombia: CES Facultad de Ciencias Humanas.

Weiss, Karen (2010). Male sexual victimization examining men's experiences of rape and sexual assault. Men and Masculinities, 12 (3), 275-298.

Wolfgang, Sofsky (2016). La organización del terror: los campos de concentración. Bueno Aires: Prometeo Libros.

Zarkov, Dubravka (2001). The body of the other man. Sexual violence and the construction of masculinity, sexuality and ethnicity in Croatian Media. En Caroline Moser y Fiona Clarck (Ed.), Victims, perpetrators or actors? Gender, armed conflict and political violence. USA: Zed Books.

Zawati, Hilmi (2007). Torture. Impunity or immunity: wartime male rape and sexual torture as a crime. Against humanity, 1 (17), 27-47.

Informes y boletines

Banco de Datos (1996-2017). Revista Noche y Niebla. Centro de Investigación y Educación Popular, Cinep.

Boletines Justicia y Paz. Comisión Intercongregacional de Justicia y Paz. 
Centro Nacional de Memoria Histórica (2011). Crímenes que no prescriben: la violencia sexual del bloque vencedores de Arauca. Bogotá: Centro Nacional de Memoria Histórica.

Centro Nacional de Memoria Histórica (2017). La guerra inscrita en el cuerpo. Informe nacional sobre violencia sexual en el conflicto armado. Bogotá: Centro Nacional de Memoria Histórica.

Corporación Excelencia en la Justicia (s. f.). Guía práctica para la investigación de los delitos sexuales contra las mujeres. Bogotá: Corporación Excelencia en la Justicia.

Defensoría del Pueblo (2017). Ruta de atención integral para asesorar e instruir a las mujeres sobrevivientes de actos de violencia sexual en el marco del conflicto armado interno y el desplazamiento forzado por la violencia de la defensoría del pueblo. Auto 009 de 2015.

Medicina Legal (1999-2017). Informes y exámenes medico legales sobre violencia sexual.

Ministerio de Protección Social (2011). Modelo de Atención Integral en Salud para víctimas de violencia sexual. Bogotá: Ministerio de Protección Social.

Nunca Más Colombia (s. f.). Memoria de Crímenes de Lesa Humanidad.

Unidad de Víctimas (s. f.). ABC del modelo de operación con enfoque diferencial y de género. Bogotá: Unidad de Víctimas.

Unidad de Víctimas (s. f.). Orientación a personas víctimas del conflicto armado desde enfoque de orientaciones sexuales e identidades de género. Manual para formadores y formadoras. Bogotá: Unidad de Víctimas.

Sentencias

Corte Suprema de Justicia, Sala de Casación Penal 2018, Frente Turbo del Bloque Bananero y del Bloque Calima de las Autodefensas Unidas de Colombia AUC.

Corte Suprema de Justicia, Sala de Casación Penal, 2012, Edgar Ignacio Fierro Flores y Andrés Mauricio Torres León, Bloque Norte de las Autodefensas Unidas de Colombia, AUC. 
Tribunal Superior del Distrito Judicial de Bogotá Sala de Justicia y Paz, 2013, Rodrigo Perez Alzate, Bloque Central Bolívar de las Autodefensas Unidas de Colombia AUC.

Tribunal Superior del Distrito Judicial de Bogotá Sala de Justicia y Paz, 2013, Fredy Rendón Herrera, Bloque Elmer Cárdenas, Región Urabá de las Autodefensas Unidas de Colombia AUC.

Tribunal Superior del Distrito Judicial de Medellin, Sala de Justicia y Paz, 2017, Ramiro Vanoy Murillo, Bloque Mineros de las Autodefensas Unidas de Colombia, AUC.

Tribunal Superior del Distrito Judicial de Bogotá Sala de Justicia y Paz, 2014, Jhon Fredy Rubio Sierra y otros, Bloque Tolima de las Autodefensas Unidas de Colombia AUC

\section{Prensa}

Álvarez, Johana (12 de diciembre de 2009). Violencia sexual como arma de guerra también es sufrida por los hombres. El Tiempo.

Caracol Radio (4 de octubre del 2008). Víctimas de alias Karina la acusan de castración.

Chynoweth, Sarah (21 de noviembre del 2017). Male rape and sexual torture in the Syrian war: 'It is everywhere'. The Guardian.

Comité de Solidaridad con los presos políticos (1974). El Libro Negro de la Represión.Colombia: Gráficas Mundo Nuevo.

Díaz, Almudena (7 de julio del 2012). Ellos también son víctimas: violencia sexual contra hombres, en situación de conflicto. United Explanation.

El Espectador (30 de enero del 2012). Con serpientes cascabel, paramilitares torturaban a sus víctimas.

El Espectador (25 de julio del 2016). Los comandantes me obligaban a estar con ellos a la fuerza.

Escárraga, Tatiana (6 de septiembre de 2014). El drama de los hombres violados en la guerra. El Tiempo. 
Storr, Will (17 de julio del 2011). The rape of men: the darkest secret of war. The Guardian.

Valero, Miriam (13 de mayo del 2012). EL silencio del hombre violado. The Prisma New Papers.

Verdad Abierta (21 de abril del 2014). Violencia paramilitar contra menores de edad en Santander. 